\title{
The Infrastructure of Public Opinion Research in Japan
}

\section{Yuichi Kubota}

\author{
University of Niigata Prefecture, Japan
}

\begin{abstract}
This article introduces the infrastructure of public opinion research in Japan by reviewing the development of polling organizations and the current situation of social surveys. In Japan, the polling infrastructure developed through the direction and encouragement of the U.S. occupation authorities. In the early 1969s, however, survey researchers began to conduct their own original polls in not only domestic but also cross-national contexts. An exploration of recent survey trends reveals that polling organizations tended to conduct more surveys during summer, in the mid-range of sample size $(1,000-2,999)$, based on random sampling (response rates of $40-50 \%)$, and through the mail between April 2011 and March 2012. The media was the most active polling sector.
\end{abstract}

\section{Keywords}

Public Opinion Research, Survey Modes, Response Rates, Japan 


\section{Introduction}

The purpose of this article is to introduce the infrastructure of public opinion research in Japan. The importance of public opinion surveys/polls is increasing because society is changing faster today than in the past. For the last several decades, surveys have been useful tools for both social scientists and practitioners who sought to capture people's changing values and norms.

Japan is not exceptional. Public opinion research was practically initiated in the country after the end of the World War II. The polling infrastructure developed through the direction and encouragement of U.S. officials in the Supreme Command of the Allied Powers. In later phases, survey researchers began to carry out original polls in both domestic and cross-national contexts.. In the following section, I briefly discuss the early phase of public opinion research.

To understand the current situation of polls, this paper also reviews recent trends and characteristics of surveys conducted by domestic polling organizations between April 2011 and March 2012. The cross-sectional exploration reveals clear patterns in the number of surveys per month, topics, polling sectors, sample size, modes, response rate, and sampling methods. In summary, domestic polling organizations conducted more surveys during summer, with samples of 1,000-2,999 respondents, using random samples, and achieved response rates of 40-50\%, Postal surveys were used most often. Among the polling sectors, the media were most active. The most popular topic for nation-wide surveys was politics, including foreign affairs and elections. For subnational surveys, the most popular topic was local administration

Japan has a reputation as one of the major countries for public opinion polls (see Nisihira, 1983). The understanding of development and current trends of Japanese polls may be helpful for other societies looking to advance their public opinion research. This article is a useful reference for the promotion of empirical studies based on survey data.

It is important to note that the structural contexts of opinion surveys differ across countries. The Japanese public opinion research infrastructure is contingent on a number of domestic circumstances, e.g., fiscal cycles, academic trends, and availability of survey subjects. In South Korea, public opinion researchers began carrying out surveys in the late 1950s (Lewis and Crossley, 1964) and most surveys are currently 
conducted by universities or outside agencies rather than the government (Min, 2006). In some other Asian countries, polling topics and the publication of results are restricted and independent surveys are banned. (see Heath et al., 2005; Rohme, 1997; Smith, 2004; Spangenberg, 2003). By focusing on Japan, this article seeks to provide a comparative perspective on the infrastructure of surveys for both major opinionresearch countries and societies with restrictions on opinion polls.

\section{Development of Public Opinion Research/Polls in Japan}

\section{First Steps of Public Opinion Polls in the post-World War II Period}

Public opinion research is one of the most important academic fields in Japan. To explore citizens' opinions and perceptions on various issues, many surveys have been administered by not only academic institutions but also organizations such as the central government, local administrative units, and the media.

After World War II, public opinion polls were initiated by the U.S. occupation authorities because they believed that political leaders' incapability to capture public attitudes had caused Japan's militarism and inclination toward expansionism., the encouragement of public opinion polls was aimed at making the populace more involved in democratic decisions and processes (Ito and Kohei, 1990; Nisihira, 1983; Yamada and Synodinos, 1994). In the occupation authorities' plan to develop domestic public opinion polls, the media, including newspaper publishing companies and broadcasting stations, were expected to play a central role in the administration of polls. ${ }^{1}$ U.S. officials relied less on the Japanese government for carrying out polls because they were concerned about the incumbent's manipulation of survey results. To promote uncensored surveys, the officials favorably supported the media to prepare for and carry out public opinion polls on their own.

\section{Cross-National Surveys}

As domestic public opinion polls accumulated, research emerged to explore people's values and norms in a comparative perspective. Cross-national surveys date back to the

\footnotetext{
${ }^{1}$ In addition to major media agencies, about 60 polling organizations appeared immediately after the war (Kuroda, 1974, p.27)
} 
1960s in Japan. These surveys were conducted with questionnaires that had been used in surveys in other countries. For instance, a survey that aimed to examine common knowledge of the young was conducted in 1963 using a questionnaire from a similar survey in France (Nisihira, 1964). In addition, questions from surveys conducted in Europe and the U.S. were used in a survey that explored religious values among the Japanese in 1968 (Nisihira, 1970).

Original questionnaires began to be employed for cross-national surveys in the 1970s. The first attempt was a survey conducted in Japan and Hawaii in 1971 that aimed to reveal similarities and dissimilarities between native Japanese and those of Japanese descent (Suzuki, 1972). A questionnaire about the characteristics of Japan, which the Japanese Institute of Statistical Mathematics (ISM) had used since 1953, was employed for this survey. This project was followed by other cross-national surveys that sought to compare the national traits of Japan and other countries. Those surveys were conducted by the Japanese government and include the World Youth Survey (1972), the International Comparison of Old-Age Persons' Attitude about Life Finance (1981), Public Opinion Survey concerning Gender Equality (1982), and the International Comparative Study on Child Raising and Family Life (1994).

More recently, Japanese scholars and practitioners of public opinion research began to be involved in large-scale cross-national (and cross-cultural) surveys simultaneously conducted in multiple countries. Their involvement in international research projects was related to the development of methods for cross-national surveys. In 1981, a nationwide survey was conducted as a part of the European Values Study (EVS). Although the EVS is mainly conducted in European countries, the 1981wave included non-European countries such as Japan and the U.S. Another largescale cross-national survey, the World Values Survey (WVS), began in Japan in 1990. Private polling companies have been playing a major role in the administration of surveys since then. In addition, the International Social Survey Program (ISSP) admitted the participation of Japan in 1992. These projects cover a variety of issues such as government, social networks and inequality, family and gender, religion, environment, nationalism, and leisure and sports. 
Despite the benefits obtained from data collection in a number of countries, there are often difficulties in constructing a questionnaire that is comparable across countries. Cultural and linguistic differences may cause problems because respondents in different countries may interpret identical questions in different ways (response incomparability). ${ }^{2}$

To compare societies that share similar values and norms, cross-national surveys targeting Asian countries have been initiated by Japanese researchers. For instance, to measure "trust" among citizens, the ISM administered a cross-national survey (East Asia Value Survey, EAVS)in five countries - Japan, South Korea, Taiwan, China, and Singapore - from 2002 to 2003 (Yoshino, 2002; Yoshino and Hayashi, 2002). The AsiaBarometer survey was conducted between 2003 and 2008 and covered more Asian countries than EAVS (Inoguchi and Fujii, 2009). Finally, the East Asian Social Surveys (EASS) has been launched to produce and disseminate survey datasets in East Asia (Iwai and Yasuda, 2009)..$^{3}$

\section{Public Opinion Polls between April 2011 and March 2012}

These cross-national surveys on social values and norms comprise an important part of public opinion polls conducted by Japanese researchers. Statistics on polls, however, tell us that many more polls have been conducted by not only universities and private companies but also by the central and local governments. To take a closer look at public opinion polls carried out by domestic organizations, this section reviews the recent state of polls in Japan.

From August to September 2012, the Cabinet Office of Japan conducted a survey of domestic polling organizations (Cabinet Office of Japan, 2012). The purpose of this survey was to capture what surveys had been conducted during the last fiscal year. ${ }^{4}$ Targeted samples included 134 national governmental organizations, 47 prefectural

\footnotetext{
${ }^{2}$ This problem is also recognized as differential item functioning (DIF) (King et al., 2003, p.568).

${ }^{3}$ For reviews on cross-national social surveys in East Asia, see also Minato (2008).

${ }^{4}$ The Office defines public opinion surveys as studies that meet the following criteria; 1) they must be designed for studying individuals; 2) they must clearly specify the intended respondents and the population from which they were drawn; 3) they should cover attitudes, interests, and opinions; 4) they should have a sample of 500 or more potential respondents; 5) they must have 10 or more questions, including demographic items; and 6) they must use a structured questionnaire (Cabinet Office of Japan, 2012; see also Yamada and Synodinos, 1994, p.119).
} 
institutions, 5810 municipalities, 250 universities, 225 media companies, and 670 private companies. Response rates vary between sectors; $8.21 \%$ for governmental organizations, $80.85 \%$ for prefectural institutions, $50.37 \%$ for municipalities, $15.20 \%$ for universities, $4.00 \%$ for media companies, and $2.09 \%$ for private companies. The number of surveys examined varies: 35 for governmental organizations, 134 for prefectural institutions, 998 for municipalities, 78 for universities, 108 for media companies, and 31 for private companies.

This unequal distribution of surveys across sectors may significantly affect survey results. Municipal surveys were overrepresented in the data, so it is likely that many surveys were carried out to explore local government issues. However, the data are informative because some common aspects are observable across sectors. The monthly frequency of surveys is contingent not only on the administrative capacity of a polling organization but also on the fiscal cycle in Japan. In addition, notwithstanding differences between sectors, surveys are designed to obtain as high a response rate as possible. In the following sections, I summarize some of the results reported by this survey.

\section{Surveys by Month}

The number of surveys in Japan varies depending on the month. Figure 1 represents the monthly percentages of the surveys conducted between April 2011 and March 2012. Although the line fluctuates between $5.13 \%$ and $11.85 \%$, it sharply rises in June-August 2011. After reaching the peak, it gradually decreases toward the end of the fiscal year. Although 95\% confidence intervals indicate a possible range of percentages, it is abreast with the estimation of monthly proportion of surveys.

Like other countries, the number of domestic polls usually increases in election seasons because many surveys are carried out to assess citizens' preference for political parties and candidates. Because there were no general elections in 2011, the rise of polls was rather a reflection of inactivity at the beginning and end of fiscal year. ${ }^{6}$ This variation is due to administrative and business cycles in Japan. Not many surveys were administered during this period because 1) migration rates are very high; 2) the

\footnotetext{
${ }^{5}$ Prefectures are equivalent to states or provinces.

${ }^{6}$ In Japan, a fiscal year begins in April and ends in March.
} 
preparation for new survey projects usually starts at the beginning of the fiscal year; and 3) polling organizations are reluctant to administer new surveys in March because they want to have the research completed by the end of the fiscal year (Yamada and Synodinos, 1994, p.121).

Figure 1

Surveys per Month (\%)

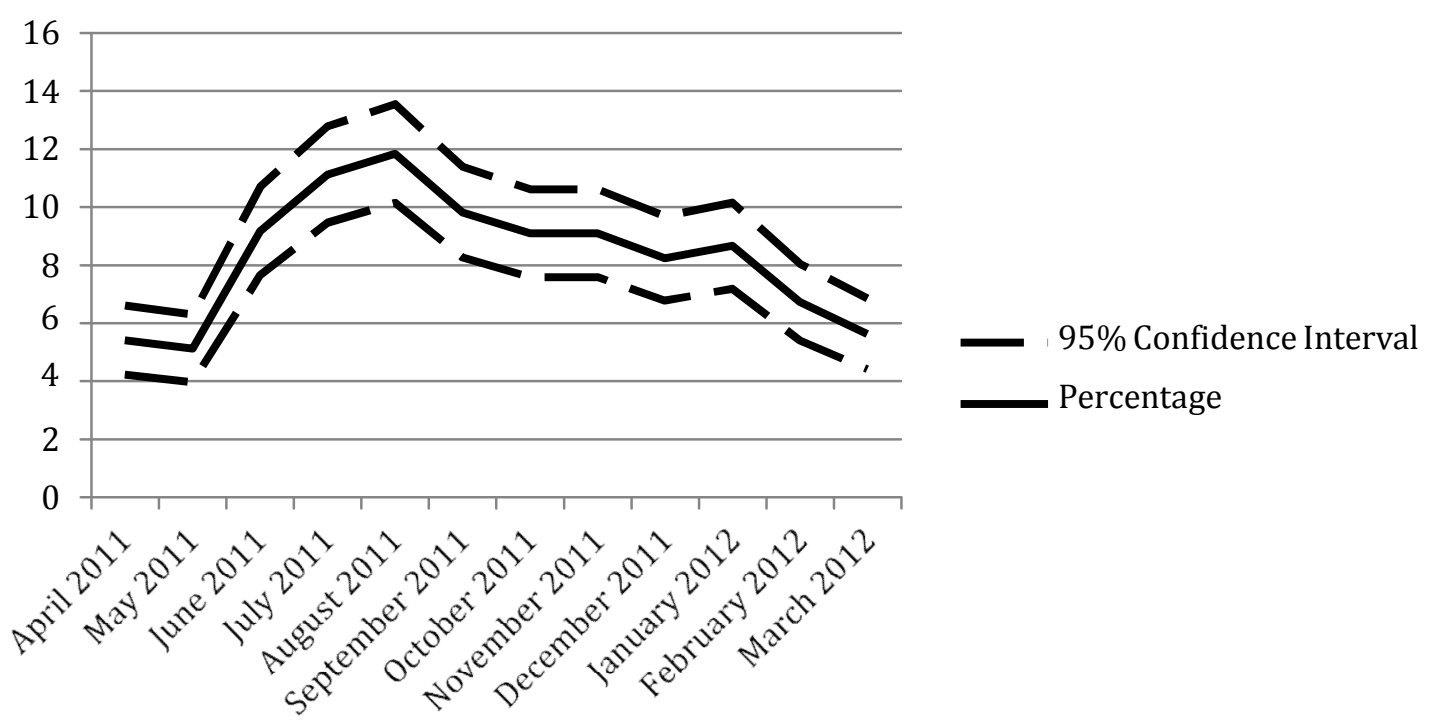

These cycles restrict the administration of polls conducted by the central and local governments more than those conducted by non-governmental polling sectors (Table 1). The government organizations carried out fewer surveys at the beginning and end of the fiscal year and more surveys around the mid-point of the year. Private companies also conducted more surveys between August and October. In contrast, more than 10\% of the surveys conducted by universities and media companies were administered in April 2011 and March 2012. 
Table 1

Surveys per Month by Sector (\%)

\begin{tabular}{|c|c|c|c|c|c|c|}
\hline & Government & Prefectures & Municipalities & Universities & Media & Private Companies \\
\hline April 2011 & 0.00 & 0.75 & 3.91 & 10.26 & 23.15 & 6.45 \\
\hline May 2011 & 0.00 & 4.48 & 5.81 & 2.56 & 3.70 & 3.23 \\
\hline June 2011 & 17.14 & 4.48 & 10.22 & 2.56 & 7.41 & 9.68 \\
\hline July 2011 & 2.86 & 10.45 & 12.63 & 7.69 & 3.70 & 9.68 \\
\hline August 2011 & 0.00 & 11.19 & 13.33 & 6.41 & 5.56 & 16.13 \\
\hline September 2011 & 2.86 & 3.73 & 10.82 & 8.97 & 10.19 & 12.90 \\
\hline October 2011 & 14.29 & 12.69 & 8.72 & 6.41 & 7.41 & 12.90 \\
\hline November 2011 & 11.43 & 18.66 & 8.12 & 7.69 & 8.33 & 3.23 \\
\hline December 2011 & 22.86 & 11.19 & 7.21 & 8.97 & 10.19 & 3.23 \\
\hline January 2012 & 8.57 & 13.43 & 7.92 & 16.67 & 4.63 & 6.45 \\
\hline February 2012 & 11.43 & 5.97 & 6.61 & 7.69 & 5.56 & 9.68 \\
\hline March 2012 & 8.57 & 2.99 & 4.71 & 14.10 & 10.19 & 6.45 \\
\hline Total & 100 & 100 & 100 & 100 & 100 & 100 \\
\hline
\end{tabular}

\section{Topics of Surveys}

Table 2 shows the topics of surveys conducted between April 2011 and March 2012.7 More than thirty percent of the nation-wide surveys were about politics/foreign affairs/elections. These issues are followed by economic concerns, i.e., monetary and tax administration, (11.56\%). Seven to eight percent of the nation-wide surveys dealt with leisure/sports/culture (8.09\%) and living manners (7.51\%). ${ }^{8}$ More than twenty percent of the sub-national surveys focused on local government. Many of these surveys were administered by prefectures and municipalities and are aimed at assessing citizens' perceptions of, (dis)satisfaction with, and demands for public services provided by the local governments. The second most frequent topic is the aging society $(9.53 \%)$ in Japan. Local polls were also carried out for public health/medical service (8.39\%), disasters/accidents/environment (7.40\%), education/childcare (7.25\%), and social security/welfare/volunteer activities (7.25\%).

\footnotetext{
7 The coding of survey topics follows that provided by the Cabinet Office of Japan (2012).

8 "Living manners indicate the attitude toward daily life and society.
} 
Table 2

Topics by Survey Scale (\%)

\begin{tabular}{lll}
\hline & Nation-wide & Local \\
\hline Politics/ForeignAffairs/Elections & 31.21 & 4.62 \\
Monetary and Tax Administration & 11.56 & 0.50 \\
Local Administration & 0.00 & 23.54 \\
Communal Societies & 0.58 & 6.26 \\
Agriculture/Forestry/Fisheries & 1.16 & 1.21 \\
Urban Problems & 1.16 & 3.27 \\
Disasters/Accidents/Environment & 5.20 & 7.40 \\
Crimes/Public Safety/Human Rights & 1.73 & 1.71 \\
Education/Childcare & 5.20 & 7.25 \\
Labor & 2.89 & 1.56 \\
Media & 2.31 & 0.07 \\
Public Health/Medical Service & 4.05 & 8.39 \\
Leisure/Sports/Culture & 8.09 & 4.05 \\
Consumption & 5.78 & 0.78 \\
Living Manners & 7.51 & 1.85 \\
Public Relations & 0.00 & 2.63 \\
Social Security/Welfare/Volunteer Activities & 2.31 & 7.25 \\
Transportation/Communication/Information & 1.73 & 2.92 \\
Women & 0.58 & 4.62 \\
Aged Society & 0.58 & 9.53 \\
Technology/Energy & 6.36 & 0.57 \\
Total & 100.00 & 100.00 \\
\hline & & \\
\hline
\end{tabular}

In the fiscal year of 2010-11, the issue of politics/foreign affairs/elections was frequently covered in nation-wide (42.55\%) and local surveys $(10.22 \%)$ because the national election was held in July 2010. Many surveys were carried out to assess citizens' preferences for political parties (see Cabinet Office of Japan, 2011). 
This topic is, important; and all polling sectors, including the government and media, conduct surveys to capture citizens' opinions about domestic politics and international relations. For instance, the Cabinet Office administers surveys about perceptions of neighboring countries at regular intervals. Without general elections, however, the number of polls about this topic decline. This fluctuation in polls dealing with elections is not new; for example, in $194757 \%$ of the newspapers' polls focused on the elections, but dropped to 7\% in the following year (Kuroda, 1974, p.27).

\section{Sectors}

Figure 2 shows the frequency of the administration of surveys by sector, including the central government, prefectures, municipalities, universities, the media, and private companies. As easily recognized, the media administered a lot more surveys than other sectors; a media agency conducted 12 surveys on average between April 2011 and March 2012. The central government and prefectures conducted surveys more than three times during the year. However, these numbers do not largely differ from those of the other sectors such as municipalities (2.45), universities (2.05), and private companies (2.21). Although there are many polls are carried out by prefectures and municipalities each year, the number of surveys per-organization is not unexpectedly large. Universities are the least salient. In Japan, academic institutions are less influential in public opinion polls despite the importance of their surveys. ${ }^{9}$

Figure 2

Frequency of the Administration of Surveys by Sector in 2011-2012

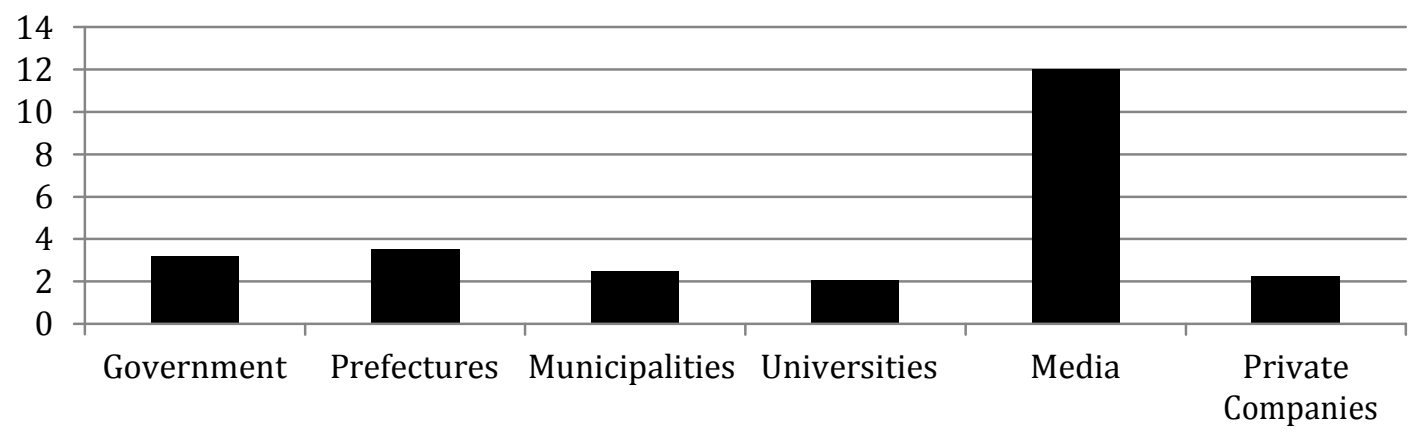

\footnotetext{
${ }^{9}$ This point was indicated by previous studies (see Kuruda, 1974, p.28).
} 


\section{Sample Size}

Nearly half of the surveys collected 1,000-2,999 responses and surveys with samples from 3,000 to 9,999 account for most of the remainder (34.90\%). Smaller and larger surveys, whose sample size were 500-999 and more than 10,000, were less frequent than these surveys ( $11.05 \%$ and $4.48 \%$, respectively).

Figure 3

Sample Size (\%)

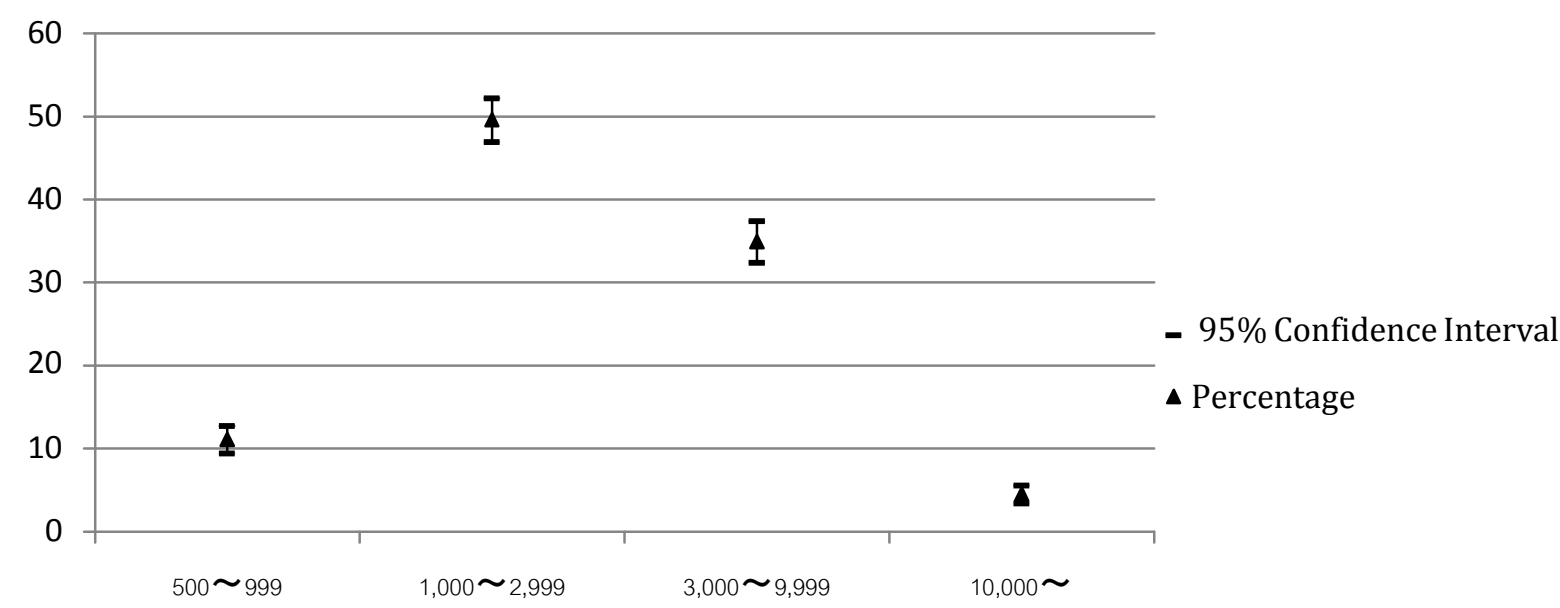

Table 3 shows sample size by polling sector and the size of surveys each sector tended to administer. For instance, the majority of the government's polls (62.86\%) were surveys with 3,000-9,999 samples. Another sector whose sample size largely fell into $3,000-9,999$ is prefecture. Their surveys with 1,000-2,999 samples account for $32.84 \%$, and larger or smaller surveys (500-999 and 10,000- samples) were not frequently conducted. More than half of the municipalities' surveys collected 1,000-2,999 samples. While one third of their surveys had a sample size of 3,000-9,999, smaller and larger surveys were underrepresented. Compared with the executive branches (i.e., government, prefectures, and municipalities), universities carried out various sizes of polls; although the most frequent category is $1,000-2,999$, the other sample sizes also account for about $20 \%$. In contrast, $70.37 \%$ of the media's surveys fell into 1,000-2,999 samples. They never conducted large-scale polls whose sample size was more than 10,000 . Whereas the media administer surveys much more frequently than other polling sectors (Figure 2), those surveys were small to mid-size. Polls conducted by 
private companies also tend to be smaller. They do administer large-scale surveys (e.g., $3,000-9,999$ and more than 10,000 samples), but the majority fell into those with $500-$ 999 samples.

Table 3

Sample Size by Sector (\%)

\begin{tabular}{lccccc}
\hline & $500 \sim 999$ & $1,000 \sim 2,999$ & $3,000 \sim 9,999$ & $10,000 \sim$ & Total \\
\hline Government & 5.71 & 14.29 & 62.86 & 17.14 & 100 \\
Prefectures & 5.97 & 32.84 & 54.48 & 6.72 & 100 \\
Municipalities & 9.82 & 52.91 & 34.47 & 2.81 & 100 \\
Universities & 25.64 & 33.33 & 23.08 & 17.95 & 100 \\
Media & 12.04 & 70.37 & 17.59 & 0.00 & 100 \\
Private Companies & 38.71 & 22.58 & 22.58 & 16.13 & 100 \\
\hline \hline
\end{tabular}

\section{Survey Modes}

Figure 4 represents the entire distribution of survey modes, and shows that the selfadministered measure was most used through mail. Accounting for $70.95 \%$, mail surveys stand out above the other modes. Less frequently used modes include individual face-to-face interviews, self-administered (other), telephone interview, and use of more than two modes. The other modes self-administered (visit) and groupadministered, are the least represented measures. The popularity of mail surveys is probably due to the difficulty in administering polls requiring visits or calls to homes of respondents as those polls entail great costs or need callbacks (Yamada and Synodinos, 1994, pp.125-6).

The breakdown of survey modes by sector reveals that mail surveys were the major method of surveys for the government, prefectures, municipalities, and private companies (Table 4). Universities employ mail surveys less frequently and instead rely more on other self-administered modes. The media rarely carried out mail surveys (1.85\%); telephone interviews were the most popular mode and face-to-face interviews were the second. Because the timely administration and publication of survey results 
are important for newspapers and broadcasting, the media would prefer quick polling to other modes of surveys.

Figure 4

Survey Modes (\%)

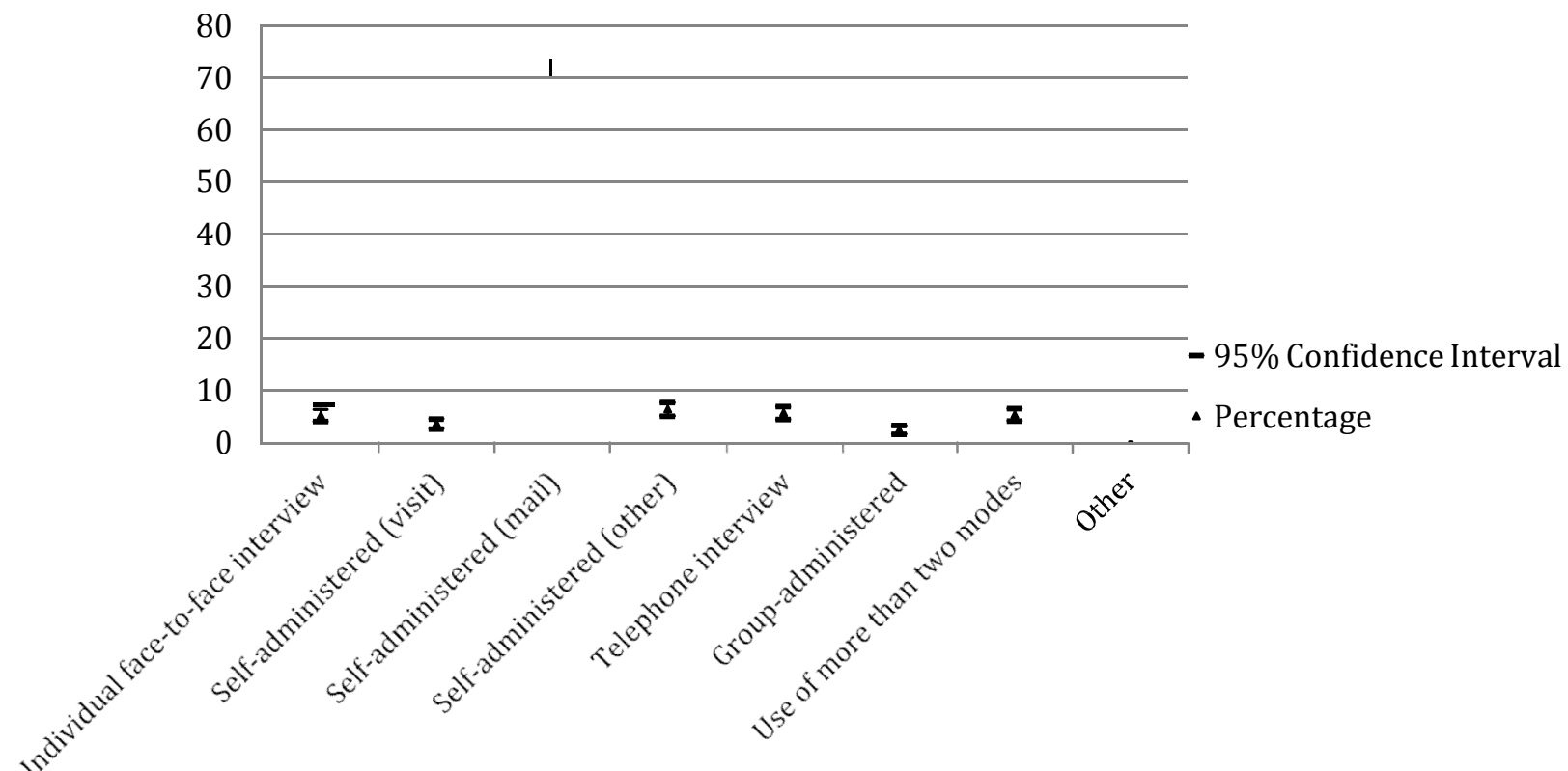

Table 4

Survey Modes by Sector (\%)

\begin{tabular}{lllllll}
\hline & Government & Prefectures & Municipalities & Universities & Media & $\begin{array}{l}\text { Private } \\
\text { Companies }\end{array}$ \\
\hline $\begin{array}{l}\text { Individual face-to-face } \\
\text { interview }\end{array}$ & 34.29 & 9.70 & 1.50 & 0.00 & 25.93 & 12.90 \\
Self-administered (visit) & 14.29 & 6.72 & 2.30 & 7.69 & 2.78 & 12.90 \\
Self-administered (mail) & 40.00 & 64.18 & 85.07 & 23.08 & 1.85 & 41.94 \\
Self-administered (other) & 2.86 & 3.73 & 5.31 & 34.62 & 0.00 & 9.68 \\
Telephone interview & 0.00 & 0.00 & 0.00 & 0.00 & 69.44 & 12.90 \\
Group-administered & 5.71 & 2.24 & 1.30 & 19.23 & 0.00 & 3.23 \\
Use of more than two & 2.86 & 13.43 & 4.11 & 15.38 & 0.00 & 6.45 \\
modes & & & & & & \\
Other & 0.00 & 0.00 & 0.40 & 0.00 & 0.00 & 0.00 \\
Total & 100 & 100 & 100 & 100 & 100 & 100 \\
\hline
\end{tabular}




\section{Response Rates}

Figure 5 represents response rates of the surveys. The majority of the surveys had response rates between 40 and 50\%. Surveys with higher response rates (50-60\%) accounted for $21.75 \%$ of surveys. Although there are also many surveys responded by $60-70 \%$ of the subjects, more than $15 \%$ of the surveys had response rates of only $30-$ $40 \%$.

Figure 5

Response Rates (\%)

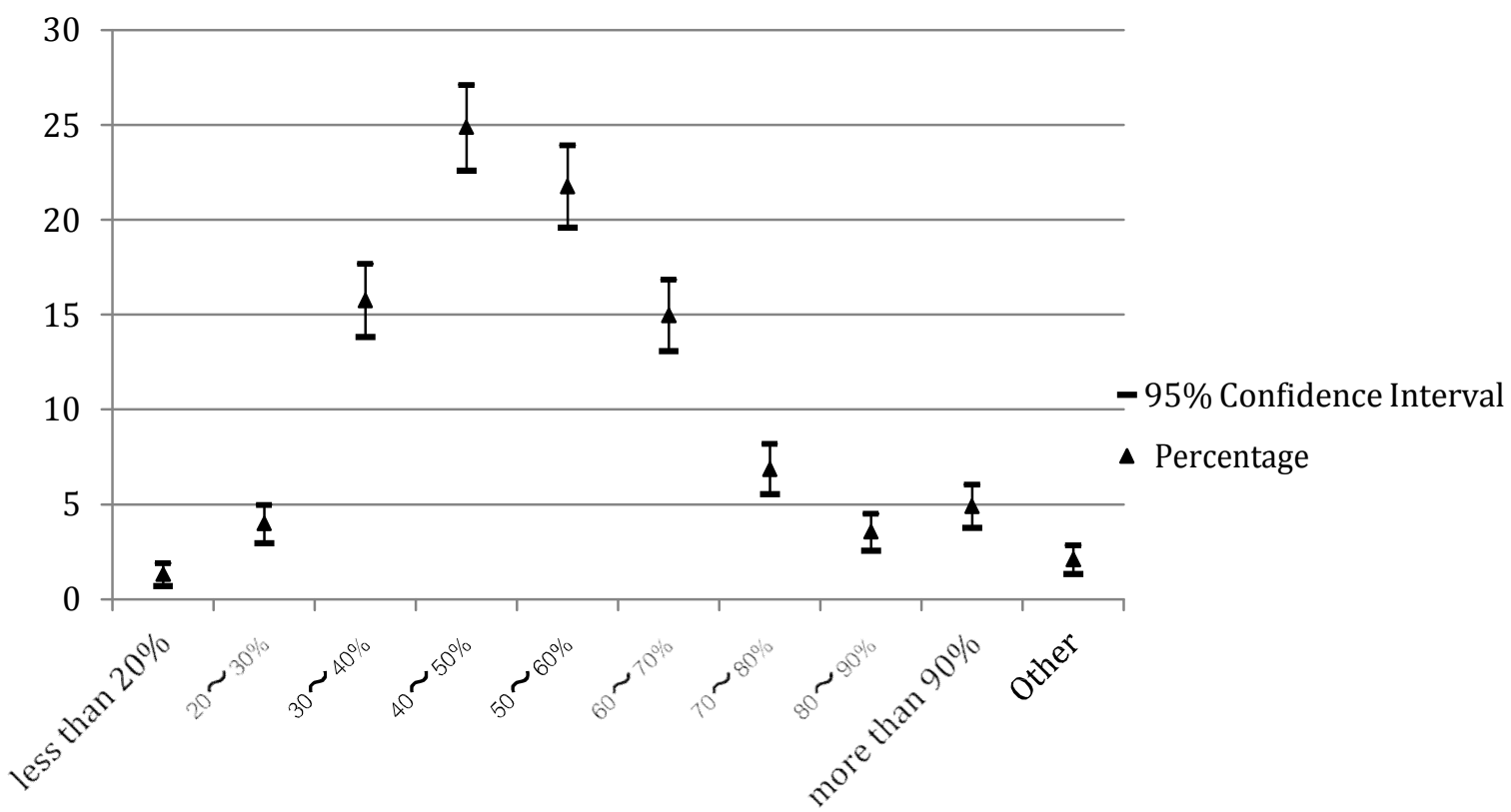

It is well known that response rates vary between survey modes (Table 5). ${ }^{10}$ The table shows that there are two components affecting response rates. First, whether face-toface interview or self-administered response after staff members' visit, personal contact with survey subjects is likely to increase response rates. More than $45 \%$ of individual face-to-face interviews fell into response rates of $60-70 \%$. Response rates of the personally delivered self-administered surveys tend to be higher compared to mail

\footnotetext{
${ }^{10}$ For response rates by size of city, gender and age for surveys conducted in Japan between 1975 and 1990, see Yamada and Synodinos (1994). Examining reasons of non-response, they conclude that the decreasing response rates reflect changes in lifestyles and attitudes toward public opinion surveys in Japan. For more recent trends in response rates in Japan, see Inaba (2007) and Synodinos and Yamada (2000) that confirm the continuous decline in response rates.
} 
Table 5

Response Rates by Survey Mode (\%)

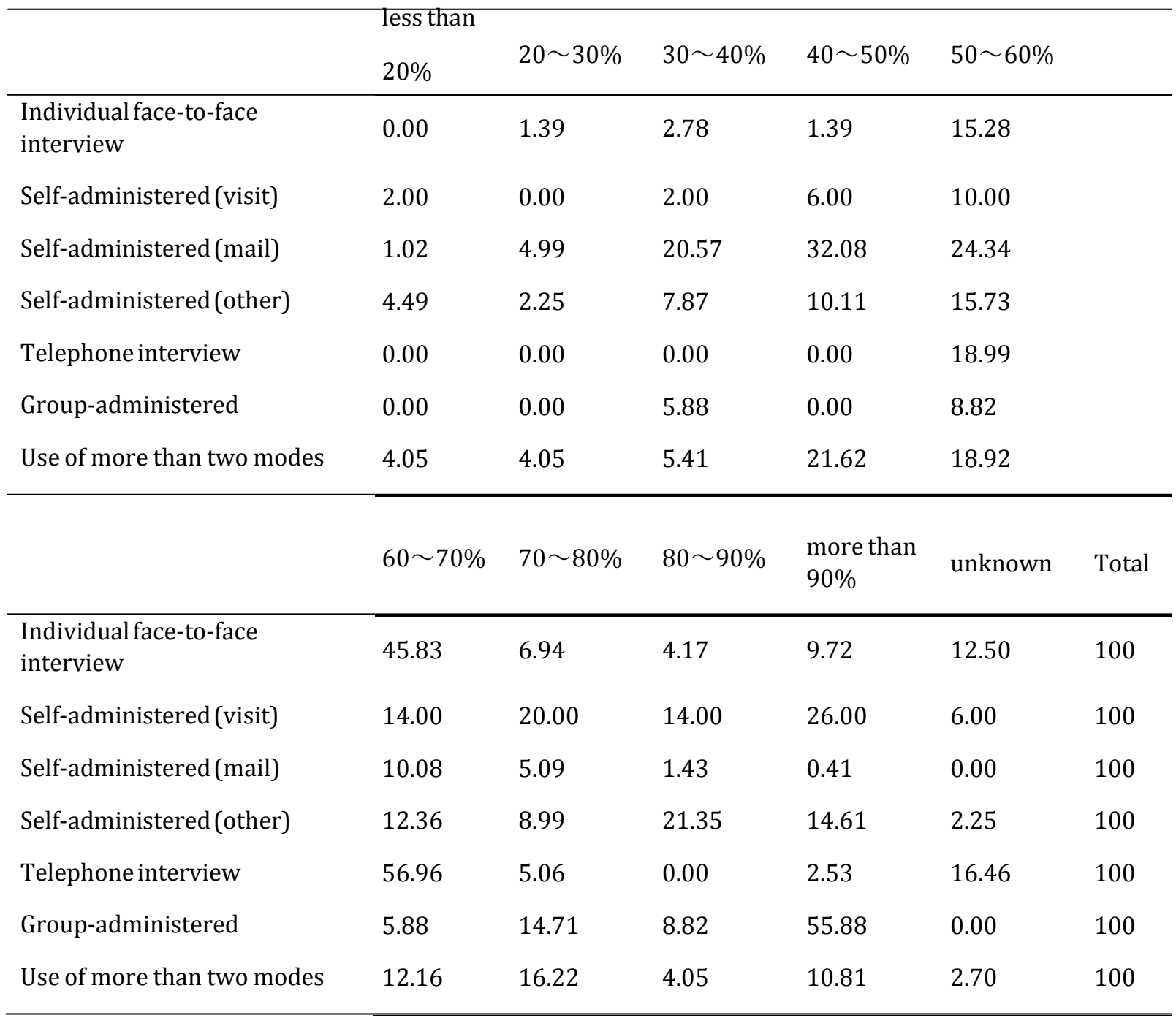

surveys; while three fourths of mail surveys fell into response rates of $30-60 \%$, the same proportion of the visit-and-self-administered surveys had response rates between $60 \%$ and $90 \%$ and above. Although respondents can complete the surveys at their convenience for both types of polls, the personal touch involved in the delivery of the survey to the respondent or someone in the household may contribute to higher response rates of the personally delivered self-administered surveys (Yamada and Synodinos, 1994, p.127). Second, the refusal to participate in an interview is not an easy option for respondents. Once questionnaires are delivered, the completion of selfadministered surveys will be left to respondents. In contrast, when withdrawing from a poll, non-self-administered surveys require the respondents to convey their unwillingness to cooperate to interviewers, which could engender disturbance in 
interpersonal exchange. In Japan, as well as face-to-face interviews, telephone interviews boast high response rates $(18.99 \%$ for response rate of $50-60 \%$ and $56.96 \%$ for $60-70 \%$ ). The table also shows that surveys administered in groups are efficient in terms of response rates; $55.88 \%$ of them obtained more than $90 \%$ response rates.

\section{Sampling Methods}

To collect samples, polling organizations largely relied on random sampling which accounts for $80.56 \%$. Although complete count and judgment sampling are also used, their proportion is far smaller than that of random sampling $(11.49 \%$ for complete count and 6.94\% for judgment sampling) (see also Yamada and Synodinos, 1994).

Figure 6

Sampling Methods (\%)

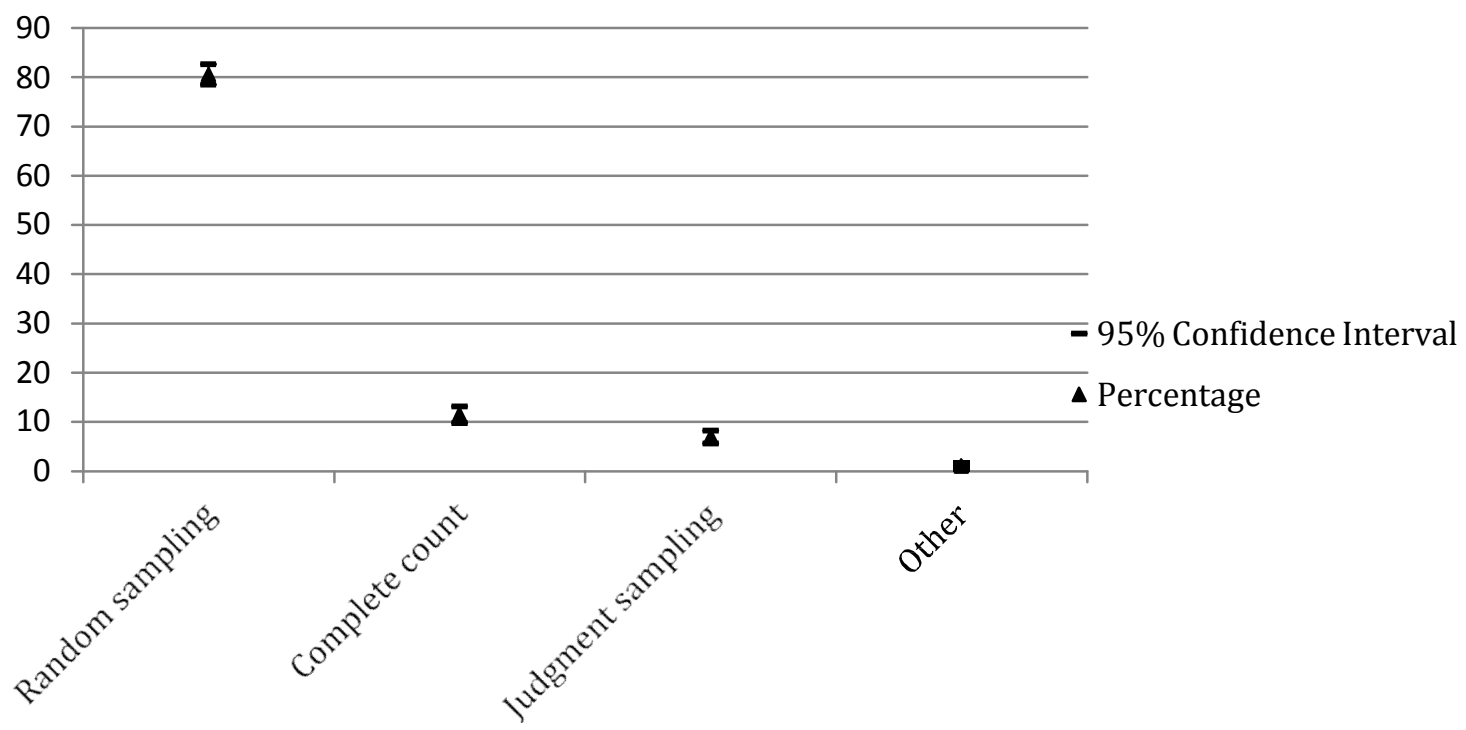

\section{Conclusion}

I have briefly described the infrastructure of public opinion research in Japan, focusing on its historical background and recent trends in surveys conducted by domestic polling organizations. This article pays less attention to a time-series analysis of the surveys, ${ }^{11}$

\footnotetext{
${ }^{11}$ For those analyses, see Inaba (2007), Synodinos and Yamada (2000), and Yamada and Synodinos (1994).
} 
and rather examines characteristics of polls carried out between the fiscal year of 201112 in-depth.

The arguments in this article are case-specific; the development of opinion research and the survey trends are deeply rooted in political, economic, and social circumstances in Japan. However, it is not impossible to draw some broader implications from the findings in the article. First, surveys are carried out for forecasting important events (e.g., elections), but they are also aimed to assess social problems. This pattern is salient in polls administered by the central and local governments. Non-governmental sectors, including universities, the media, and private companies, are also actively engaged in independent surveys that reflect concerns among the population. Second, the development of opinion-research infrastructure is path-dependent. The active role of the Japanese media in the administration of surveys would not be independent of historical background; U.S. officials purposively promoted the capabilities of newspaper publishing companies and broadcasting stations in the occupation period. This favorable promotion has strengthened the media's competence in administering surveys. Third, although survey designs are tailored to scientific requirements, the administration of opinion polls is bounded by sociopolitical contexts. In the fiscal year of 2011-12, most surveys were carried out with samples randomly selected from the population. In contrast, timing and modes of surveys are restricted by domestic circumstances such as the fiscal cycle and the availability of samples, which is susceptible to changes in lifestyle. Opinion polls rest on the balance of scientific scrupulosity and practical feasibility.

In response to the findings of this article, cross-national exploration of survey trends would be a possible next step. This study largely owes the data to the statistics provided by a branch of the Japanese government. Because the feasibility of comparative analysis depends on the accessibility to relevant data, it may not be easy to promptly put this idea into practice. However, at least, findings and methods laid out in this article could be a starting point for comparative study of infrastructures of public opinion research across not only Asian countries but also all over the world. 


\section{Reference}

Cabinet Office of Japan. (2011). The Present Circumstances of Public Opinion Polls. Retrieved September 2, 2013, from http://www8.cao.go.jp/survey/genkyou/h23/h22-genkyou/index.html.

Cabinet Office of Japan. (2012). The Present Circumstances of Public Opinion Polls. Retrieved August 29, 2013, from http://www8.cao.go.jp/survey/genkyou/h24/h23genkyou/index.html.

Heath, Anthony, Stephen Fisher, and Shawna Smith. (2005). The Globalization of Public Opinion Research. Annual Review of Political Science, 8, 297-333.

Inaba, Akihide. (2007). Problems Relating to Declining Response Rates to Social Survey Research in Japan: Trends After 2000. International Journal of Japanese Sociology, 16 (1), 10-22.

Inoguchi, Takashi and Seiji Fujii. (2009). The AsiaBarometer: Its Aim, Its Scope and Its Development. In Valerie Møller, Denis Huschka and Alex C. Michalos (eds.), Barometers of Quality of Life Around the Globe: How Are We Doing? Social Indicators Research Series Vol.33 (pp.187-232). Netherlands: Springer.

Ito, Youichi and Shinsaku Kohei. (1990). Practical Problems in Field Research in Japan. In Uma Narula and W. Barnett Pearce (eds.), Cultures, Politics, and Research Programs: An International Assessment of Practical Problems in Field Research (pp.89121). Hillsdale: Lawrence Erlbaum.

Iwai, Noriko and Tokio Yasuda. (2009). Family Values in East Asia: A Comparison among Japan, South Korea, China, and Taiwan based on East Asian Social Survey 2006 (in Japanese). Kyoto: Nakanishiya Shuppan.

King, Gary, Christopher J. L. Murray, Joshua A. Salomon, and Ajay Tandon. (2003). Enhancing the Validity and Cross-Cultural Comparability of Measurement in Survey Research. American Political Science Review, 97 (4), 567-583.

Kuroda, Yasumasa. (1974). Public Opinion Surveys in Japan: Prospects for a Data Library. Public Data Use, 2 (3), 26-29.

Lewis, Ralph and Helen M. Crossley. (1964). Opinion Surveying in Korea. Public Opinion Quarterly, 28 (2), 257-272.

Min, Crystal Dawn. (2006). Existence Challenged, Progress Envisioned, Culture Compromised: The Effects of Western Influences on Traditional Values in South Korea. Unpublished paper.

Minato, Kunio. (2008). Cross-national Social Survey in East Asia: World Values Survey, ISSP, AsiaBarometer, Asian Barometer, East Asia Value Survey and EASS. JGSS Research Series 7.

Nisihira, Sigeki. (1964). Le Niveau des Connaisances de la Jeunesse au Japon: La Comparaison avec les pays Occidentaux. Sondages, 26e, année. 
Nisihira, Sigeki. (1970). Les Attitudes des Japonais envers la Religion. Annals of the Institute of Statistical Mathematics, Supplement 6.

Nisihira, Sigeki. (1983). Public Opinion Polling in Japan. In Robert M. Worcester (ed.), Political Opinion Polling: An International Review. London: Macmillan.

Rohme Nils. (1997). The Freedom to Publish Opinion Polls: Report on a Worldwide Study. Amsterdam: European Society for Opinion and Marketing Research (ESOMAR).

Smith, Tom W. (2004). Freedom to Conduct Public Opinion Polls around the World. International Journal of Public Opinion Research, 16 (2), 215-223.

Spangenberg, Frits. (2003). The Freedom to Publish Opinion Polls: Report on a Worldwide Update. Amsterdam: European Society for Opinion and Marketing Research (ESOMAR).

Suzuki, Tatsuzo. (1972). Ethnic Japanese in Honolulu, Hawaii: Relevance to National Traits Surveys (in Japanese). Gakujutsu-Geppou, 24 (11), 37-44.

Synodinos, Nicolaos E., Shigeru Yamada. (2000). Response Rate Trends in Japanese Surveys. International Journal of Public Opinion Research, 12 (1), 48-72.

Yamada, Shigeru and Nicolaos E. Synodinos. (1994). Public Opinion Surveys in Japan. International Journal of Public Opinion Research, 6 (2), 119-138.

Yoshino, Ryozo. (2002). A Time to Trust? A Study on Peoples' Sense of Trust from a Viewpoint of Crossnational and Longitudinal Study on National Character. Behaviormetrika, 29 (2), 231-260.

Yoshino, Ryozo and Chikio Hayashi. (2002). An Overview of Cultural Link Analysis of National Character. Behaviormetrika, 29 (2), 125-141.

\section{Biographical Note}

Yuichi KUBOTA is Lecturer at Center for Policy Research, University of Niigata Prefecture in Japan. His research focuses on civil war, public opinion, and the political economy of development in Asia. He has published a book (Armed Groups in Cambodian Civil War: Territorial Control, Rivalry, and Recruitment, Palgrave Macmillan, 2013) and several research articles in these fields.

He can be reached at: kubota@unii.ac.jp

Date of the submission: 2013-09-12

Date of the review result: 2013-10-07

Date of the decision: 2016-10-14 